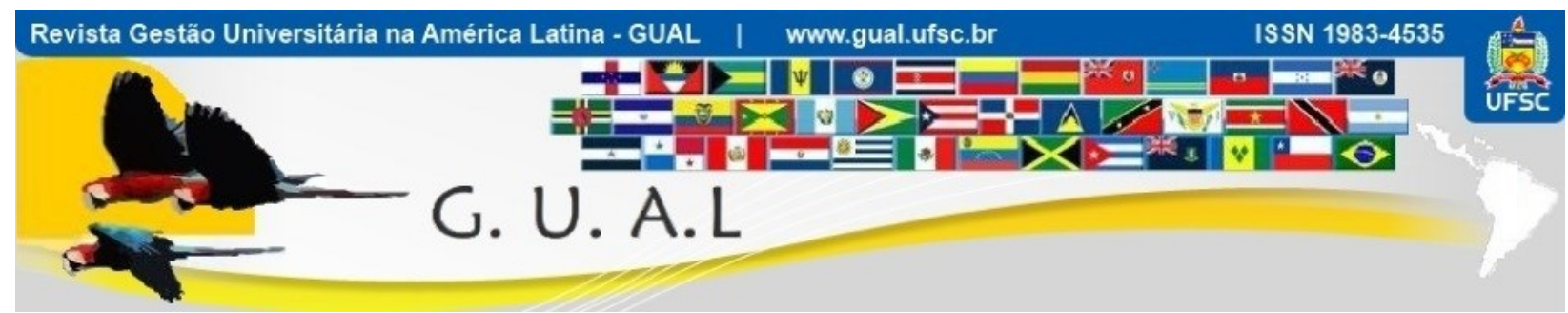

DOI: http://dx.doi.org/10.5007/1983-4535.2017v10n4p227

\title{
MARKETING NO ENSINO SUPERIOR: ATRIBUTOS VALORIZADOS PELOS DISCENTES DE CURSO DE ESPECIALIZAÇÃO
}

\section{MARKETING IN HIGHER EDUCATION: ATTRIBUTES VALUED BY STUDENTS OF SPECIALIZATION COURSES}

Clayton Daniel Masquietto, Doutorando Fundação Municipal de Ensino de Piracicaba - FUMEP Universidade Metodista de Piracicaba - UNIMEP masquietto@yahoo.com.br

Nádia Kassouf Pizzinatto, Doutora Universidade Metodista de Piracicaba - UNIMEP $\underline{\text { nkp@,nadiamarketing.com.br }}$

Andrea Kassouf Pizzinatto, Doutora Universidade Metodista de Piracicaba - UNIMEP marketingandrea@yahoo.com.br

Rosana Borges Zaccaria, Doutora Universidade Metodista de Piracicaba - UNIMEP rbzaccar@unimep.br

Recebido em 25/novembro/2016

Aprovado em 16/outubro/2017

Sistema de Avaliação: Double Blind Review 


\title{
RESUMO
}

O mercado de trabalho competitivo e a busca contínua pelo saber atrai estudantes recémformados e profissionais graduados a se especializarem através dos cursos de pós-graduação lato sensu. Entretanto, o aumento significativo de instituições que oferecem esse tipo de serviço faz com que estudos a respeito do marketing educacional venham a se tornar uma ferramenta necessária para a captação de alunos. Neste sentido o objetivo principal do presente estudo é identificar os atributos que levam os alunos de uma instituição de ensino superior particular do município de Piracicaba à escolher seus cursos de pós-graduação lato sensu. Com este intuito foi realizada uma pesquisa descritiva com abordagem quantitativa, por meio da aplicação de um questionário levantando fatores motivadores de comunicação, qualidade e conveniência, e questionado sobre a procura por outras instituições. Os resultados apontam que os alunos que afirmaram comparar a instituição e seus cursos com outros oferecidos no mercado tomaram suas decisões pautados pelos três tipos de atributos de motivação estudados. Ou seja, os alunos buscam uma combinação de boas informações, qualidade e conveniência para definirem suas escolhas. Assim, os resultados podem auxiliar a definição de estratégias das IES em termos de marketing educacional e política concorrencial.

Palavras chave: Instituições de Ensino Superior. Pós-graduação Lato Sensu. Marketing Educacional. Atributos Motivacionais.

\begin{abstract}
The competitive job market and the pursuit for knowledge attract new graduates and graduated professionals to specialize through specialization courses. However, the significant increase in the number of institutions offering this type of service makes studies about education marketing a necessary tool for attracting students. In this sense, the main objective of the present study is to identify the features that lead the students of a private higher education institution of the city of Piracicaba to choose their specialization courses. For this purpose a descriptive survey was carried out with a quantitative approach, by means of applying a questionnaire collecting motivating factors of communication, quality and convenience, e and questioning the demand for other institutions. The results indicate that the students who affirmed comparing the institution and its courses with others offered in the market made their decisions based on the three types of motivational attributes studied. That is, students seek a combination of good information, quality and convenience to define their choices. On this basis, the results can help the definition of higher education institution strategies in terms of education marketing and competitive politics.
\end{abstract}

Keywords: Higher Education Institutions. Specialization Courses. Education Marketing. Motivational Attributes. 


\section{INTRODUÇÃO}

O mundo dos negócios mostra-se cada vez mais exigente, fazendo com que os profissionais do mercado sejam constantemente pressionados a se atualizar e buscar novas soluções para os novos problemas que aparecem nas organizações diariamente, uma vez que são cobrados continuamente pelo seu desempenho.

Neste sentido, conforme Gomes et al (2010), a educação continuada passa a ser uma das estratégias usadas pelos profissionais para manterem sua empregabilidade, já que é um processo de qualificação profissional que pode ser planejado a médio e longo prazo ou à medida que vão acontecendo às mudanças nos processos de trabalho. Para Mainardes et al (2007) tal situação levou ao crescimento do número de instituições de ensino, principalmente de educação superior.

Porém, Tauil e Mainardes (2013) lembram que a expansão das instituições ensino superior (IES) e consequentemente a elevação do número de diplomados em cursos de graduação fez com que a certificação deste nível de ensino deixasse de ser suficiente.

Assim, a pós-graduação lato sensu aparece como opção para os profissionais de nível superior, que tem por objetivo a especialização profissional, tratando-se de cursos destinados ao aperfeiçoamento nas partes que se compõem um ramo profissional ou científico. Porém, ainda é um modelo de ensino relativamente novo no Brasil quando comparado com outros países, sendo assim pouco estudado, o que o torna um rico tema para a realização do presente estudo.

Para Meneghelli (2011) o mercado de trabalho competitivo e a busca contínua pelo saber atraem estudantes recém-formados e profissionais que desejam o título de especialista, elevando a demanda por tais cursos levando muitas IES a oferecerem esta modalidade de ensino no Brasil, até como saída para a estagnação da procura por cursos de graduação.

Entretanto, o aumento significativo de instituições que oferecem esse tipo de serviço no Brasil faz com que estudos a respeito do marketing educacional venham a se tornar uma ferramenta necessária à gestão da IES no intuito de melhor trabalhar a captação de alunos também para os cursos de pós-graduação lato sensu.

Seguindo este raciocínio o objetivo principal deste estudo foi identificar os atributos que levam os alunos de uma instituição de ensino superior particular a escolher seus cursos de pós-graduação lato sensu, permitindo um melhor planejamento das estratégias de prospecção e captação de novos candidatos para os cursos de tal instituição. 
Este trabalho, além desta linhas introdutórias, apresenta uma revisão teórica que trata desde do cenário da educação superior no país, passando pela contextualização dos cursos de pós graduação lato sensu e pela implantação do marketing nas instituições que compõem o setor do ensino superior e, até tratar dos atributos que influenciam na escolha da instituição por parte dos alunos. Em seguida é descrita a metodologia utilizada, que foi a realização de uma survey em uma instituição de ensino superior do município de Piracicaba-SP. Por fim, os resultados alcançados e as considerações finais do estudo.

\section{FUNDAMENTAÇÃO TEÓRICA}

O referencial da presente pesquisa foi pautado em quatro aspectos: ensino superior, ensino de pós-graduação no Brasil, marketing educacional e atributos motivacionais.

\subsection{ENSINO SUPERIOR NO BRASIL}

No final da década de noventa, as instituições de ensino superior (IES) privadas brasileiras tiveram um grande crescimento alavancado pela expansão do ensino médio, conquistando a aproximadamente $70 \%$ do mercado de ensino superior no país (NUNES et Al, 2008). Segundo Nunes et al (2008) tal demanda crescente contribuiu para distanciar as instituições em relação às práticas de marketing, devido à inexistência de competição, uma vez que o mercado possuía um grande contingente de potenciais clientes, pronto para demandar todos os cursos oferecidos e pagar as mensalidades praticadas.

Porém, com a entrada do século XXI, muitas mudanças culturais ocorreram no cenário brasileiro, abrangendo desde os campos da ciência, da tecnologia, como também, a vida social, econômica e educacional dos brasileiros, fazendo com que as pessoas das diversas classes socioeconômicas tivessem acesso aos mais variados bens e serviços de consumo. Conforme Scaglione e Piza (2011) tais mudanças, fortalecidas pelo crescimento econômico do país, atingiram também o mercado educacional, já que grande parcela da população passou a procurar por níveis mais elevados de escolaridade, com grande destaque ao ensino superior.

Este cenário de busca pela educação superior no país elevou consideravelmente o número de instituições privadas criadas a partir do final da década de 1990. Em 2014 as instituições de ensino superior (IES) privadas representavam 87,4\% do total de IES brasileiras e absorveram aproximadamente 2,5 milhões de novos alunos (INEP, 2015). 
Entretanto, tal situação levou a uma expectativa de demanda que não se concretizou, ocasionando um excesso de vagas de ensino superior, ou seja, a demanda por vagas nos cursos superiores não foi proporcional ao aumento das vagas oferecidas, gerando vagas ociosas na maioria das IES, em especial nas particulares, o que por sua vez preconiza um ambiente de possível crise, conforme relatam Scaglione e Piza (2011), Scarpin et al (2010), Nunes et al (2008) e Lima (2006).

Por exemplo, segundo Lima (2006), entre 2005 e 2010, o crescimento populacional previsto, na faixa etária de 18 a 24 anos, tendia a encolher $24 \%$, reduzindo a população com algum potencial de investir em formação superior. Ou seja, a quantidade de candidatos potenciais para custear a educação superior privada mostra-se menor do que o número de vagas disponíveis.

Assim, de acordo com Scarpin et al (2010), a expansão das IES particulares no Brasil teve duas importantes consequências: por um lado trouxe benefícios a muitos alunos ao criarem oportunidades de ingressar no curso superior, por outro lado acirrou a concorrência para as IES, tanto em cursos presenciais, quanto em cursos à distância.

Para Scaglione e Piza (2011) uma das principais causas dessa questão está na facilidade com que a Lei $n^{0} 9.394$ de 1996, de Diretrizes e Bases da Educação (LDB), permitiu a abertura de IES por todo o país, provocando uma grande disputa pelos estudantes por parte das Instituições e tornando o ambiente educacional brasileiro mais competitivo.

A este cenário deve-se acrescentar que novos competidores, como as universidades empresariais de capital aberto e as universidades virtuais, passaram a surgir no mercado, até então ocupado pelas IES tradicionais. No caso das universidades empresariais, com a abertura de capital para investidores as IES transformam a educação e o ensino em mercadorias, competindo no mercado de ações com seus produtos, como as demais empresas privadas de capital aberto. Já as universidades virtuais invadem o mercado até então ocupado unicamente pelas IES tradicionais.

Conforme Scaglione e Piza (2011), estes novos competidores possuem grande capacidade de investimento, utilizando de tal poderio para focar nos segmentos tradicionais, concorrendo com as IES privadas na captação dos mesmos estudantes. Porém além do cenário competitivo delineado a cima, Nunes et al (2008) lembram que também devem ser levadas em conta tendências emergentes, tais como a educação continuada e a educação de cunho profissionalizante. 
Diante de tal situação a palavra competitividade que parecia distante do setor de ensino por muitos anos hoje se faz presente no dia-a-dia das IES. Neste sentido, Scarpin et al (2011), afirmam que a maior concorrência obrigou as instituições de ensino a adotar uma postura mais comercial, para melhor entender as demandas de mercado, e assim oferecer cursos compatíveis com as necessidades das empresas que virão a utilizar dos profissionais formados por elas.

As modificações no sistema educacional do país, com o crescimento acelerado de vagas ofertadas por parte das universidades particulares, acarretou um aumento da competitividade no sentido de atrair e manter o número de alunos necessários para ocupar de forma eficiente a capacidade instalada na instituição. O novo segmento que surgiu como alternativa foi o dos cursos de Pós Graduação. Sobre eles se discorre a seguir.

\subsection{ENSINO DE PÓS-GRADUAÇÃO NO BRASIL}

Para Tauil e Mainardes (2013) a expansão das IES particulares facilitou o ingresso das pessoas em cursos superiores, porém por outro lado a elevação do número de diplomados em cursos de graduação criou uma situação em que a certificação deixou de ser suficiente para determinar a excelência do profissional. Neste sentido as organizações no Brasil passaram a exigir qualificações específicas, que levem a uma maior aplicabilidade do conhecimento em situações no dia-a-dia.

Frente a este cenário surge um novo nicho de mercado para a atuação das IES que se materializa através dos cursos de pós-graduação lato sensu. Costa (2007) define os cursos lato sensu como cursos de pós-graduação de orientação ampla e aberta, em comparação aos cursos stricto sensu orientados para a formação acadêmica. Ou seja cursos lato sensu, também denominados cursos de especialização, envolvem aperfeiçoamento profissional em nível de pós-graduação.

A pós-graduação lato sensu é um modelo de ensino relativamente novo no Brasil quando comparado com outros países e, de acordo com Costa (2007), no contexto da formação em nível superior no Brasil, surge como a primeira alternativa para os estudantes graduados que pretendem orientar suas carreiras para o exercício de uma atividade profissional. Tal característica somada ao dinamismo advindo de sua natureza aberta resultou o crescente aumento da oferta destes cursos a partir da década de 1990 pelas IES no mercado nacional. 
Levando em conta o caráter seu recente a pós-graduação lato sensu, ainda é um tema pouco abordado na literatura, o que não tira sua relevância. Neste sentido, Tauil e Mainardes (2013) apontam que diversos autores ressaltam a importância da continuidade dos estudos, bem como a necessidade de investimento contínuo em qualificação e aprendizado.

Ou seja, ao serem cobrados continuamente com o intuito de melhorar seu desempenho o profissionais do mercado se veem pressionados pela atualização e pela busca por soluções de diversos novos problemas organizacionais, o que encontram na continuidade e especialização de seus estudos já que fórmulas e soluções do passado não resolvem os problemas atuais do dia-a-dia.

Portanto, a pós-graduação lato sensu é focada nos profissionais de nível superior que buscam uma especialização visando conhecimentos sobre determinada área de atuação, ou, como aponta Monteiro (2008), trata-se de cursos destinados ao aperfeiçoamento e à especialização, em temas que compõem um determinado ramo profissional.

Conforme Bandeira et al (1998) a Lei da Reforma Universitária no 5540/68 já havia aberto as postas para a pós-graduação lato sensu, possibilitando uma maior exploração desses cursos pelas instituições de ensino superior, possibilitando ir além dos cursos stricto sensu. Porém o conservadorismo por muito tempo desestimulou em impediu mudanças no ensino, uma vez que para implantação dos novos cursos se fazia necessário utilizar a criatividade para se criar e manter um padrão de qualidade e inovação no ensino, neste sentido o curso de MBA da EAESP/FGV foi um dos primeiros a seguir este caminho.

A criatividade na implantação de cursos lato sensu vem da necessidade de se segmentar o público já graduado de forma a atender as necessidades do aluno que trabalha em empresas. Bandeira et al (1998) entende que pede mudanças na estrutura de ensino garantindo um enfoque no desenvolvimento de habilidades gerenciais. Assim, o curso deve ser mais mais compacto, com um ritmo mais intenso e com uma cobrança menor na proficiência em termos de revisão bibliográfica e maior na demonstração aplicação prática de conhecimentos.

Desta forma autores como Kotler e Fox (1995) e Cobra e Braga (2004) indicam que a busca contínua do saber por parte de estudantes recém-formados e profissionais que desejam o título de especialista dentro de um cenário competitivo de mercado, levou a muitas IES oferecerem esta modalidade de ensino no Brasil rompendo com o conservadorismo inicial.

Porém o aumento significativo de instituições que passaram a oferecer esse tipo de serviço no Brasil e a facilidade de acesso trazem a mesma competitividade vista nos cursos de graduação 
para este novo nicho de mercado, fazendo com que estudos a respeito do marketing educacional sejam essenciais para a gestão da IES, a fim de otimizar a captação de alunos também em relação à estes cursos.

\subsection{MARKETING EDUCACIONAL}

Com a queda da demanda na graduação e o investimento em cursos de pós graduação, as IES particulares encararam a necessidade de profissionalizar sua gestão administrativa, financeira e comercial, com o objetivo de buscar diferentes maneiras de atrair e reter seus estudantes, desenvolvendo novas estratégias de marketing que permitissem sua continuidade no mercado.

Para Caetano, Oliveira e Silva (2004), dentre as estratégias a serem utilizadas as instituições de ensino passaram a pensar na aplicação do marketing para se manterem vivas neste setor também tão competitivo e se destacarem, despertando o interesse do candidato na hora da escolha da instituição.

Neste sentido, marketing pode ser definido como o processo de planejamento, execução e controle de produtos voltado para alcançar os objetivos organizacionais. Para Trevisan (2001), de maneira geral marketing é diretamente relacionado com vendas e historicamente as formas de vender os produtos eram feitas corpo a corpo, porém, hoje, o marketing cumpre um papel muito maior.

Em um primeiro momento, o conceito de marketing focalizava a organização, posteriormente, as atenções voltaram-se para o cliente e, mais recentemente, surgiu o foco também nas estratégias e nos sistemas em que a empresa está inserida. Portanto, conforme Trevisan (2001), marketing é mais que venda, propaganda e promoção para criar e manter a demanda, ou seja, é a habilidade de planejar e administrar as relações de troca da empresa com o seu mercado.

Já para Kotler e Armstrong (2007), marketing é uma atividade humana que tem como objetivo satisfazer necessidades e desejos por meio do processo de trocas. Tal definição é complementada pela American Marketing Association (AMA) quando define: "Marketing é o conjunto de atividades, processos e instituições que têm por objetivo criar, comunicar, entregar e promover trocas que tenham valor para os consumidores, clientes, parceiros de negócio e a sociedade como um todo" (apud SCAGLIONE; PIZA, 2011). 
Porém, deve-se levar em conta que as primeiras definições para marketing tinham como foco produtos tangíveis, apenas mais tarde alguns autores, como Kotler e Levy (1969) ampliaram tal conceito, passando a incluir também os serviços, e as organizações sem fins lucrativos. Neste sentido, segundo Caetano e Oliveira e Silva (2004), marketing educacional passou a ser a expressão do momento no ramo educacional, mais especificamente das instituições particulares, tendo em vista o cenário competitivo atual.

No entanto, conforme Bravin e Ikeda (2010) o marketing sempre foi tratado com reservas no contexto educacional, sendo inclusive, visto como algo prejudicial que tem como objetivo único vender e estimular o consumo. Com isto, os gestores da área encontram barreiras na busca por ações que poderiam levar a melhor atendimento aos alunos, pais, empresas e sociedade como um todo uma oferta mais adequada de seus serviços.

Também no Brasil, embora desde meados dos anos 1950 a palavra marketing seja empregada no setor empresarial, ela tardou a ser usada nas instituições educacionais tendo em vista posições controversas quanto à sua adequação à missão das escolas. De acordo com Trevisan (2001), no Brasil, em torno de 60 anos atrás, marketing era uma palavra desconhecida; entretanto disseminou-se com grande velocidade e passou a fazer parte do jargão administrativo. Entretanto, nas instituições acadêmicas, apesar de contribuir para a difusão desse conceito, a palavra marketing acabou não sendo aplicada com a mesma intensidade e frequência com que se fazia nas empresas.

Assim, a aplicação do marketing nas instituições educacionais encontra-se dividida em dois lados. De um lado há uma concepção favorável que, conforme Trevisan (2001), vê sua contribuição com a instituição na sua missão educacional ao desenvolver programas viáveis, com uma política de preços coerente e comunicação eficaz, possibilitando um aumento de satisfação do seu público-alvo. De outro lado, os opositores consideram o marketing incompatível com a missão da educação, argumentando que seria, inclusive, desnecessário, se as pessoas reconhecessem que a educação foi boa para elas. Para Dessotti et al (2013), tal concepção torna-se um entrave para a implantação do marketing, já que é assumida por muitas pessoas que estão ligadas à gestão educacional, indireta ou diretamente.

Segundo Kotler e Fox (1994) a noção de incompatibilidade entre o marketing e a missão educacional parte de profissionais que criam entraves por sentirem que os valores e técnicas educacionais estão em direção contrária aos valores e técnicas das empresas, ou seja, acreditam que uma IES não pode ser considerada como uma empresa, devendo assim ser 
administrada de forma diferente. Os autores ainda lembram que muitos continuam achando que o marketing diz respeito apenas à área de vendas. Tal visão, quando levada para uma IES, causa discussões que dificultam sua implantação, mesmo sem sequer conhecer o verdadeiro conceito e a real funcionalidade do marketing.

Bravin e Ikeda (2010) lembram que o marketing deve ser visto como uma ferramenta administrativa que tem como objetivo facilitar as trocas no sentido de beneficiar os agentes nelas envolvidos. Porém, como qualquer ferramenta, pode ser utilizada de forma positiva ou negativa dependendo de quem a utiliza, não cabendo generalizações sobre a validade de sua utilização em determinado setor de atividade.

Cada vez torna-se mais inquestionável a importância do marketing para a sobrevivência das empresas, independentemente do ramo de atuação; assim, o mesmo pode ser, hoje em dia, atribuído às instituições de ensino. Pois se a razão de ser de tais empresas são seus clientes, a razão de existir para as instituições de ensino são seus alunos. Sem eles, como afirma Trevisam (2001), as escolas fechariam suas portas, levando em conta o ambiente hipercompetitivo atual, em que tanto empresas como IES entraram na era do cliente.

Neste sentido, conforme Kotler e Fox (1994), uma IES deve ser vista como uma organização/empresa, deixando de lado esta diferença que foi criada socialmente e que alimenta as barreiras que dificultam que as instituições ensino possam receber os benefícios concorrenciais advindos da aplicação dos conceitos e estratégias de marketing.

Ou seja, faz-se necessária uma mudança de conceitos, pois quando a IES passa a ser vista como uma organização que depende de contatos com seus clientes efetivos e potenciais para conseguir manter-se sólida e competitiva, a aplicação do marketing será visualizada como essencial. Isto se dá principalmente no momento atual, em que se inverte a lógica do mercado, ou seja, não mais os clientes correm atrás dos bens escassos, mas sim os vendedores de bens e serviços buscam por clientes. Neste sentido, a eficácia do marketing seja em instituições educacionais, outras empresas industriais e comerciais ou, até mesmo, filantrópicas, depende do quanto satisfaz as necessidades e desejos de seus clientes.

No mercado educacional encontram-se instituições que se preocupam com a sua clientela enquanto outras sequer sentem-se sensibilizadas. De acordo com Trevisan (2001), essas últimas são típicas de instituições burocráticas, que se mantêm no mercado enquanto o consumidor não tiver outra opção. Por outro lado, aquelas que se preocupam com o seu público consumidor, atual e potencial, constantemente preocupam-se em estudar como o 
consumidor posiciona-se diante da instituição e qual imagem que ele tem do produto ou serviço em diferentes aspectos.

De qualquer forma deve-se levar em conta que a definição de marketing aplicada a serviços, como no caso da educação, é bem mais complexa do que aquela aplicada a produtos tangíveis. Dentre as características básicas da gestão dos serviços podem-se destacar: intangibilidade, eles não podem ser provados antes de serem comprados; variabilidade, possuem elevada variação de resultados dependendo que que os executa e do momento que executa; inseparabilidade, são produzidos e consumidos simultaneamente; e perecibilidade, não pode ser estocados (COUTINHO, 2007).

Entende-se, portanto, que o marketing educacional está ligado diretamente com as bases e conceitos do marketing de serviços. Sendo assim, Dessotti et al (2013), indicam que algumas ações de marketing podem ser facilmente aplicadas pelas IES, tais como: analisar o mercado por meio do uso de tecnologias para facilitar a segmentação do mesmo; atender o público alvo, levando em consideração o preço que será cobrado e de acordo com o que será oferecido ao aluno; ter um local que atenda à demanda; promover o serviço de forma que todos possam visualizar. Porém, como afirmam Carvalho e Berbel (2001), não se deve esquecer que todas as ações de marketing devem ser responsáveis e com compromissos sociais que atendam aos objetivos da instituição para que realmente venham a impactar positivamente em toda estrutura educacional.

Segundo Michael (1997) em sistemas de ensino superior, independentemente do nível, caracterizados por uma grande competição, encontra-se uma maior participação de instituições privadas, uma maior liberdade e capacidade de estudantes potenciais em escolher uma instituição de maior confiança no mercado e uma maior autonomia institucional e liberdade acadêmica. Assim, Mainardes et al (2007) afirmam que o cenário para as IES é caracterizado pela competição por estudantes e pelo foco em clientes, induzindo os administradores de instituições de ensino superior a ficarem mais competitivos. Tal pressão acarreta mudanças nas IES e leva-as a implementar diferentes estratégias de mercado.

Entretanto, Michael (1997) lembra que os estudantes não estão na mesma posição de um consumidor comum, uma vez que a compra realizadas por eles não é voltada à satisfazer uma necessidade imediata, e sim necessidades a serem supridas no longo prazo e muitas vezes até serão conhecidas no decorrer do consumo. Ou seja, o ensino superior trabalha em um mercado imperfeito, no qual o público-alvo procura selecionar os cursos com base em alguns 
atributos que agreguem valor à oferta de cada instituição, com base em sua ótica particular. Sobre isso discorre-se a seguir.

\subsection{ATRIBUTOS DE ATRATIVIDADE DE ALUNOS NO ENSINO SUPERIOR}

A competição atual combinada com as características do mercado descritas acima força as IES a buscarem adotarem estratégias de marketing mais inovadoras e práticas, com o objetivo de defender e aumentar sua participação de mercado. Neste sentido o conceito de marketing passa a ser utilizado com o propósito de captar, conquistar e manter alunos.

Embora, como qualquer outro negócio, as IES passaram a conviver com a constante necessidade de atrair novos estudantes devido frente à competitividade deve-se levar em consideração que o produto/serviço que elas oferecem é diferenciado, pois trata-se de algo intangível que é o conhecimento.

Para Scarpin et al (2010) o principal das IES é a formação, atualização e especialização profissional, com atividades de ensino e educação na disseminação do conhecimento, atendendo às demandas de suas comunidades internas e externas. Neste sentido, saber quais os atributos diferencia uma IES de outra, passou a ser um fator estratégico para atração de seu público.

Pensando nos atributos de escolha que afetam a atratividade de alunos das IES para seus diferentes cursos alguns estudos foram realizados na área de marketing educacional desde o fim dos anos 1990, tais como: Alves (1999); Franco (2000); Mund et al (2001); Trevisan (2001); Palácio et al (2002); Alfinito e Granemann (2003); Bronemann e Silveira (2004); Cobra e Braga (2004); Piñol (2004); Mavondo et al (2005); Thies e Bianchi (2005); Walter et al (2005); Ciurana e Leal Filho (2006); Miranda e Domingues (2006); Pereira e Forte (2006); Seeman e O’Hara (2006); Mainardes et al (2007); Bergamo et al (2010); Muriel e Giroletti (2010); Scarpin et al (2011); Tauil e Mainardes (2013), conforme pode ser verificado no Quadro 01. 
Quadro 01 Atributos de atratividade de alunos no ensino superior

\begin{tabular}{|c|c|}
\hline Atributos de Atratividade & Autores \\
\hline $\begin{array}{l}\text { Imagem, Marca, Tradição, Status e } \\
\text { Prestígio Acadêmico da IES }\end{array}$ & $\begin{array}{l}\text { Palácio et al (2002); Alfinito e Granemann (2003); Alves (1999); } \\
\text { Bronemann e Silveira (2004); Franco (2000); Scarpin et al } \\
\text { (2011); Muriel e Giroletti (2010) }\end{array}$ \\
\hline Excelência em Serviços & $\begin{array}{l}\text { Mainardes et al (2007); Pereira e Forte (2006); Miranda e } \\
\text { Domingues (2006); Bronemann e Silveira (2004); Muriel e } \\
\text { Giroletti (2010) }\end{array}$ \\
\hline Inovação e Criatividade & $\begin{array}{l}\text { Mavondo et al (2005); Pereira e Forte (2006); Muriel e Giroletti } \\
\text { (2010) }\end{array}$ \\
\hline Infraestrutura e Instalações & $\begin{array}{l}\text { Alfinito e Granemann (2003); Bronemann e Silveira (2004); } \\
\text { Bergamo et al (2010); Mund et al (2001); Tauil e Mainardes } \\
\text { (2013) }\end{array}$ \\
\hline Currículos dos Cursos & $\begin{array}{l}\text { Ciurana e Leal Filho (2006); Piñol (2004); Muriel e Giroletti } \\
\text { (2010) }\end{array}$ \\
\hline $\begin{array}{l}\text { Satisfação e Empregabilidade dos Ex- } \\
\text { alunos }\end{array}$ & $\begin{array}{l}\text { Seeman e O'Hara (2006); Bronemann e Silveira (2004); Alfinito } \\
\text { e Granemann (2003) }\end{array}$ \\
\hline Informações de Amigos e Colegas & $\begin{array}{l}\text { Alves (1999); Bronemann e Silveira (2004); Muriel e Giroletti } \\
\text { (2010) }\end{array}$ \\
\hline Qualificação do Corpo Docente & $\begin{array}{l}\text { Pereira e Forte (2006); Bronemann e Silveira (2004); Thies e } \\
\text { Bianchi (2005); Piñol (2004); Walter et al (2005) }\end{array}$ \\
\hline Localização & $\begin{array}{l}\text { Miranda e Domingues (2006); Bronemann e Silveira (2004); } \\
\text { Mund et al (2001); Alfinito e Granemann (2003); Cobra e Braga } \\
(2004)\end{array}$ \\
\hline $\begin{array}{l}\text { Reconhecimento do Mercado de Trabalho } \\
\text { e da Sociedade }\end{array}$ & $\begin{array}{l}\text { Mund et al (2001); Bronemann e Silveira (2004); Scarpin et al } \\
\text { (2010); Alfinito e Granemann (2003); Muriel e Giroletti (2010) }\end{array}$ \\
\hline Mensalidades Acessíveis & $\begin{array}{l}\text { Trevisan (2001); Alfinito e Granemann (2003); Bergamo et al } \\
\text { (2010); Mund et al (2001); Muriel e Giroletti (2010) }\end{array}$ \\
\hline $\begin{array}{l}\text { Utilização de Propaganda em Mídia de } \\
\text { Massa }\end{array}$ & Muriel e Giroletti (2010) \\
\hline
\end{tabular}

Fonte: Elaborado pelos autores utilizando a revisão da literatura.

\section{METODOLOGIA}

Levando em conta o objetivo principal deste estudo de identificar os atributos que levam os alunos de uma instituição de ensino superior particular a escolher seus cursos de pós-graduação lato sensu foi realizado em um primeiro momento um estudo de natureza exploratória fundamentado em revisão da literatura e focado em aprofundar o conhecimentos sobre as causas que levaram ao crescimento deste tipo de curso no país, suas características e os fatores de atratividade. Em seguida realizou-se uma pesquisa quantitativa, descritiva e transversal, por meio de levantamento de dados primários, com a aplicação de questionário com questões fechadas e semiabertas junto aos alunos de uma instituição de ensino superior 
particular do município de Piracicaba-SP, buscando confrontar a teoria com a realidade da organização.

A pesquisa exploratória foi planejada no sentido de proporcionar uma maior familiaridade com o problema em estudo, buscando torna-lo mais explícito e permitindo construir elementos para análise. Desta forma o estudo exploratório assumiu seu objetivo principal, conforme Malhotra (2001), que é possibilitar a compreensão do problema enfrentado pelo pesquisador.

Já a pesquisa descritiva, de acordo com Vieira (2002), visa conhecer e interpretar a realidade sem nela interferir, tendo um caráter conclusivo descritivo. Assim o estudo exploratório foi executado com o interesse em observar os elementos de análise construídos na pesquisa exploratória na realidade, procurando descrevê-los, classificá-los e interpretá-los.

Num segundo momento, foi realizada uma survey, ou seja uma investigação do tipo Descritivo Estatístico, junto aos alunos de uma IES que se encontra há 48 anos no mercado educacional e desde 2012 oferece cursos presenciais de pós-graduação lato sensu, contando com 132 alunos ativos, população alvo deste estudo. No primeiro semestre de 2015 cinco deles encontravam-se em andamento na unidade de ensino sendo eles: Infraestrutura de Saneamento Básico, Gestão de Recursos Hídricos, Gestão Construção Civil, Gestão da Qualidade e Produtividade e Engenharia de Segurança do Trabalho.

Considerando a população em questão, foram coletados dados junto a 82 alunos matriculados em quatro dos cursos oferecidos pela instituição, perfazendo $62 \%$ do universo de pesquisa. Neste sentido participaram da pesquisa todos os alunos presentes em sala na última semana de aulas do semestre letivo.

A coleta de dados foi realizada a partir da aplicação de um modelo de questionário estruturado, com perguntas fechadas e semiabertas, dividido em três partes. A primeira parte do instrumento de pesquisa procurou entender as fontes de informação dos alunos em relação à instituição, ou seja, os motivadores de comunicação; posteriormente questionou-se a procura dos respondentes por outras instituições, seguindo-se o questionamento sobre os motivos decisórios que os levaram a escolher a IES pesquisada, isto é, motivadores de conveniência ou de qualidade.

Os dados coletados com a aplicação do questionário foram analisados levando em consideração os atributos no Quadro 01 do referencial teórico, buscando descrever as 
informações e motivações que levaram os alunos a escolher a instituição em análise e interpretar os resultados sob à luz da teoria sobre o assunto.

O Quadro 02 apresenta como foi realizada a amarração para a análise entre os atributos teóricos e os fatores motivadores levantados através do questionário, numa adaptação do modelo de Mazzon (apud Telles, 2001).

Quadro 02 Matriz de Amarração em atributos de atratividade levantados na revisão teórica e os motivadores levantados pelo questionário de pesquisa

\begin{tabular}{|l|l|}
\hline \multicolumn{1}{|c|}{ Atributos de Atratividade (Teoria) } & \multicolumn{1}{c|}{$\begin{array}{c}\text { Atributos Motivadores } \\
\text { (Questionário) }\end{array}$} \\
\hline Imagem, Marca, Tradição, Status e Prestígio Acadêmico da IES & Imagem de Qualidade da Instituição \\
\hline Excelência em Serviços & Imagem de Qualidade da Instituição \\
\hline Inovação e Criatividade & Mídias Digitais; Cursos Diferenciados \\
\hline Infraestrutura e Instalações & Estrutura Física \\
\hline Currículos dos Cursos & Grade Curricular \\
\hline Satisfação e Empregabilidade dos Ex-alunos & Indicação de Ex-alunos \\
\hline Informações de Amigos e Colegas & Indicação de Amigos \\
\hline Qualificação do Corpo Docente & Corpo Docente \\
\hline Localização & Localização \\
\hline Reconhecimento do Mercado de Trabalho e da Sociedade & Indicação de Empresas \\
\hline Mensalidades Acessíveis & Preço mais Acessível \\
\hline Utilização de Propaganda em Mídia de Massa & Mídias Tradicionais \\
\hline
\end{tabular}

Fonte: Elaborado pelos autores, numa adaptação de Telles, 2001.

\section{APRESENTAÇÃO E ANÁLISE DOS RESULTADOS DA PESQUISA}

Como mencionado na revisão bibliográfica o aumento significativo de instituições que passaram a oferecer cursos de pós-graduação lato sensu no Brasil e a facilidade de acesso acirraram a competitividade neste novo nicho de mercado educacional, fazendo-se importante analisar como se dá procura por parte dos alunos e o que o leva a decidir por determinado curso e instituição.

A Tabela 01 apresenta os diferentes fatores motivadores considerados na escolha dos alunos pelos cursos da instituição estudada na presente pesquisa, bem como, se estes alunos consultaram outras IES para tomarem suas decisões. Neste sentido 37\% dos participantes informaram consultar concorrentes antes de sua escolha. 
Tabela 01 Fatores motivadores na escolha pela IES pesquisada segundo alunos que consultaram ou não outras instituições

\begin{tabular}{|l|r|c|c|c|c|c|}
\hline \multirow{2}{*}{ Motivadores } & \multicolumn{3}{|c|}{ Consultou Outra Instituição } & \multicolumn{2}{c|}{ Total } \\
\cline { 2 - 7 } & \multicolumn{1}{|c|}{ Sim } & \multicolumn{1}{c|}{ \% } & Não & \% & Respondentes & \% \\
\hline Mídias Digitais & 27 & 72,97 & 9 & 20,00 & 36 & 43,90 \\
\hline Imagem de Qualidade da Instituição & 15 & 40,54 & 18 & 40,00 & 33 & 40,24 \\
\hline Localização & 17 & 45,95 & 15 & 33,33 & 32 & 39,02 \\
\hline Grade Curricular & 18 & 48,65 & 12 & 26,67 & 30 & 36,59 \\
\hline Indicação de Empresas & 4 & 10,81 & 16 & 35,56 & 20 & 24,39 \\
\hline Preço mais Acessível & 13 & 35,14 & 5 & 11,11 & 18 & 21,95 \\
\hline Indicação de Ex-alunos & 5 & 13,51 & 7 & 15,56 & 12 & 14,63 \\
\hline Indicação de Amigos & 2 & 5,41 & 5 & 11,11 & 7 & 8,54 \\
\hline Mídias Tradicionais & 5 & 13,51 & 1 & 2,22 & 6 & 7,32 \\
\hline Cursos Diferenciados & 3 & 8,11 & 3 & 6,67 & 6 & 7,32 \\
\hline Estrutura Física & 1 & 2,70 & 3 & 6,67 & 4 & 4,88 \\
\hline Corpo Docente & 0 & 0,00 & 3 & 6,67 & 3 & 3,66 \\
\hline Total de Respondentes & $\mathbf{3 7}$ & 100,00 & 45 & 100,00 & 82 & 100,00 \\
\hline
\end{tabular}

Fonte: Elaborado pelos autores analisando os questionários respondidos.

Analisando a Tabela 01 pode-se notar que entre os alunos que consultaram outras instituições o principal motivador de escolha foram as informações coletadas nas mídias digitais, com aproximadamente $73 \%$ de apontamento, seguido pela grade curricular dos cursos, localização e preços mais acessíveis. Já entre os alunos que não consultaram outras IES o motivador mais citado foi o da imagem de qualidade da instituição, seguido pela indicação de empresas e pela localização.

Aliás, a imagem da instituição é um atributo valorizado também para os que consultaram outra instituição. O segundo atributo mais importante na decisão de não consultar outros cursos preponderou entre aqueles que receberam indicação de empresas, $(35,56 \%)$ do que se depreende que poderiam estar investindo no funcionário e interferiram no processo decisório.

A composição da Grade Curricular foi atributo relevante entre os que consultaram outras IES $(48,65 \%)$ mais do que entre os que não consultaram outras instituições. Esse resultado depõe a favor dos cursos da instituição investigada.

A localização também é um atributo de peso, tanto entre os que consultaram $(45,95 \%)$ quanto entre os que não consultaram outras IES (33,33\%).

A seguir serão apresentados os resultados do total de alunos pesquisados, apresentados na última coluna da Tabela 1, relacionando-os com a fundamentação teórica. 
Assim, em torno de $40 \%$ dos alunos informaram ter como ponto motivador na escolha a imagem de qualidade da instituição. Segundo Palácio et al (2002), a imagem da marca tem influência considerável no comportamento de consumidores, sendo um fator de decisivo ao se adquirir inúmeros tipos de produtos e serviços. Neste sentido, as IES brasileiras precisam investir em uma imagem irrepreensível para manter a competitividade no mercado, se distinguindo de seus concorrentes e fortalecendo sua imagem de prestígio e qualidade.

De maneira geral a imagem de uma instituição de ensino é formada por meio de dois componentes diferentes, o cognitivo e o afetivo e os fatores que determinam esses componentes influenciam a imagem global, porém, conforme Mainardes et al (2007), o componente afetivo é mais influente. Sendo assim, a imagem da IES transmitida pelos estudantes atuais e ex-alunos afetam a atração de estudantes potenciais, sendo que tal imagem é construída pela qualidade e excelência do serviço prestado.

Desta forma, Muriel e Giroletti (2010) apontam que a atratividade funciona desde que a marca seja forte e haja identificação dos alunos com ela devido ao projeto de qualidade oferecida pela instituição, o que pode ser garantido pelo estabelecimento de melhores práticas pedagógicas, que aumentam o desempenho dos estudantes, por exemplo.

A inovação e criatividade, segundo Mavondo et al (2005) e Pereira e Forte (2006), é outro ponto para atratividade de alunos, uma que a inovação é um aspecto básico para uma organização se orientar para o mercado. A inovação, neste sentido, pode ser definida como a geração, aceitação e implementação de novas ideias, processos, produtos ou serviços. No caso das IES ela pode ganhar forma, além da adoção de novas práticas pedagógicas, no oferecimento de cursos diferenciados com temas pouco explorados pela concorrência, sendo um fator motivador para aproximadamente 7\% dos alunos entrevistados.

Para Muriel e Giroletti (2010), a inovação e a criatividade também devem estar na forma de divulgar os cursos e se comunicar com os candidatos a alunos, fazendo-se necessária a utilização de meios de comunicação via web. Sabe-se que, cada vez mais, os candidatos ao ensino superior são usuários da Internet. Cada vez mais o público em geral capta informações pela web, faz a sua inscrição por ela e não se sente inseguro seque em realizar operações comerciais por este meio. Considerando a instituição em análise, quase $44 \%$ dos alunos tomaram conhecimento dos cursos por meio de mídias digitais, o que facilita as ações de captação de alunos, sendo que eles acessam o site da IES e fazem o registro para obter informações por e-mail sobre assuntos que lhes interessam. 
A grade curricular dos cursos foi apontada por aproximadamente $37 \%$ dos alunos participantes da pesquisa como aspecto motivado em suas escolhas. Neste sentido, Ciurana e Leal Filho (2006), citaram que incluir assuntos atuais e de relevância social e global, como a sustentabilidade, nos currículos dos cursos oferecidos pelas IES podem também funcionar como fator de atração de alunos, tratando-se de um diferencial atrativo ao melhorar a qualidade dos conteúdos oferecidos.

Avançando na questão da grade curricular Muriel e Giroletti (2010) apontam que para muitos coordenadores de curso a formação voltada para o mercado de trabalho é algo muito valorizado pelos alunos potenciais, sendo assim um ponto importante a ser considerado na elaboração de conteúdos e metodologias voltadas para a formação de determinado mercado. Porém, não se pode deixar de lado a formação ampla e vinculada aos aspectos comportamentais, tão valorizada pelo consumidor de serviços educacionais, pois as duas formações desejadas não são incompatíveis. Porém, a preocupação com os conteúdos curriculares deve ser constantes frente à velocidade das mudanças no mercado de trabalho, uma vez que os próprios autores lembram que as dez especializações profissionais mais procuradas em 2010 não existiam seis anos antes.

De acordo com Piñol (2004), além da composição e atualização das disciplinas, um dos atributos também valorizado pelos alunos de pós-graduação é o de professores com vivência no mercado de trabalho; corroborando esta informação Thies e Bianchi (2005) citam a preferência dos alunos por docentes dinâmicos e disponíveis. Na presente pesquisa apenas $4 \%$ dos alunos indicaram este fator como importante em sua escolha. Porém, Walter et al (2005), apontam que as práticas pedagógicas e o corpo docente, embora não sejam valorizados no momento da entrada do aluno na IES, são fatores que ganham importância no decorrer do curso, com a permanência do aluno na IES e com futuras indicações para novos alunos.

No presente estudo a indicação de ex-alunos é apontada como fator importante na escolha da instituição por $15 \%$ dos pesquisados. Segundo Seeman e O'Hara (2006), embora a reputação acadêmica de uma escola tenha sido o fator principal de atratividade aponta em seu estudo, outros indicadores de desempenho não podem ser deixados de lado, como a satisfação de pessoas com experiência em determinada escola e o percentual de ex-alunos empregados. Dentro destes aspectos o fator empregabilidade é de suma importância para a escolha de cursos de pós-graduação, tendo em vista fatores já mencionados na revisão bibliográfica, tal 
como o fato de que a posse de diploma de curso superior não é mais garantia de vaga no mercado de trabalho.

Desta forma, para Scarpin et al (2010), a empregabilidade do curso escolhido é complementada pelo valor atribuído ao diploma de determinada IES no mercado de trabalho, pois ambos são fatores que contribuem para o aluno de especialização compreender que as possibilidades de crescimento profissional ofertadas pela IES em que estuda é um dos principais aspectos de construção da marca da organização. Neste sentido, em torno de $24 \%$ dos alunos entrevistados apontaram que a indicação da empresa foi um fator importante na sua escolha pela instituição.

Outro fator importante na atração de alunos é a divulgação "boca a boca", a indicação, feita por alunos, ex-alunos, amigos e familiares a outros candidatos, aparece como uma prática habitual no processo de captação de alunos, segundo Muriel e Giroletti (2010). O aluno potencial usa essa estratégia para reduzir suas incertezas na hora de adquirir um serviço de alto risco e custo como um curso de pós-graduação, desta forma a indicação assume um peso considerável na captação e retenção de alunos. Portanto informações de amigos e colegas são fatores importantes na escolha de uma IES, como afirma Alves (1999) e na presente pesquisa isto foi apontado por quase $9 \%$ dos alunos como forma de buscar melhores informações para a sua decisão.

Já a propaganda veiculada pela mídia tradicional de massa, de acordo com Muriel e Giroletti (2010) é apontada como necessária para a captação de novos alunos. Usando-se para isto, além da propaganda em rádio e TV, outdoor, jornais, faixas, mala-direta, panfletagem, cartazes e folders, se tornado ferramentas e ações presentes no cotidiano das IES. Na instituição em questão em torno de 7\% dos alunos afirmam que chegaram à instituição por meio de propaganda na mídia de massa. Embora esta participação se apresente relativamente menor em relação às indicações, seja de amigos, alunos e ex-alunos ou empresa, deve-se considerar, conforme Kimura et al (2008), as mídias tem uma importante função de contágio para que as informações cheguem até os atores que farão a indicação.

Segundo Tauil e Mainardes (2013) a infraestrutura física da IES é outro ponto determinante para a escolha por cursos nas IES tendo inclusive uma forte influência no índice de evasão dos alunos de instituições privadas. Dentre as variáveis que se enquadram neste iten Scarpin et al (2011) destacam o fator segurança no campus como diferencial competitivo para 
a IES. Em relação à instituição estudada 5\% dos alunos afirmaram levar a estrutura física em consideração em sua escolha.

De acordo com Cobra e Braga (2004), os aspectos de acesso e localização, no sentido de apontatar a proximidade ao trabalho ou residência do aluno, são motivos pessoais que atendem à busca por conveniência por parte do consumidor. No caso da presente pesquisa aproximadamente $39 \%$ dos alunos da instituição analisada citou tal aspecto como importante na sual escolha.

Outro fator motivador ligado à conveniência é o valor da mensalidade, neste sentido Trevisan (2001) reforça que os alunos buscam por mensalidades adequadas ao curso pretendido, atraentes e acessíveis. Neste sentido, muitas IES aderem aos descontos como estratégia importante para atrair novos alunos e competir no mercado. Entretanto, Muriel e Giroletti (2010), lembram que se deve reconhecer que a concessão de descontos quando realizada de forma indiscriminada pode comprometer as finanças da instituição, na medida em que eles reduzem as receitas provenientes da cobrança das mensalidades, podendo acarretar posteriormente uma redução de qualidade dos cursos. Na instituição pesquisada, $22 \%$ dos alunos disseram levar em conta os preços mais acessíveis para escolher onde cursar sua especialização.

\section{CONSIDERAÇÕES FINAIS}

A presente pesquisa teve como objetivo identificar os atributos que levam os alunos de uma instituição de ensino superior particular do município de Piracicaba a escolher seus cursos de pós-graduação lato sensu. $\mathrm{O}$ estudo demonstrou a importância de atributos motivacionais de comunicação, de qualidade e de conveniência como fatores de concorrência, sendo um importante ponto de análise para as IES que oferecem este tipo de curso.

Em relação aos atributos de comunicação se destacam as mídias digitais, porém a comunicação boca a boca, ao somar as indicações de empresas, amigos e ex-alunos, também aparece como um importante atributo motivador ao transparecer segurança para os alunos que recebem a indicação. Já as mídias tradicionais são as que menos se destacam como motivador direto, embora não se possa descartar sua importância em termos de manter a lembrança em relação aos cursos e a instituição.

Dentre os atributos de qualidade a imagem da instituição e a grade curricular dos cursos aparecem como principais fatores citados pelos alunos como importantes para as suas 
escolhas. Por outro lado, entre os fatores de conveniência destaca-se a localização da instituição seguida pelos preços mais acessíveis.

Pensando em concorrência, os alunos que afirmaram comparar a instituição e seus cursos com outros oferecidos no mercado apontaram que a atuação nas mídias sociais e as grades curriculares dos cursos são importantes fatores de competição, seguidos da localização e da imagem da instituição. Sendo assim a instituição não pode se preocupar com apenas um tipo de atributo, pois os alunos buscam uma combinação de boas informações, qualidade e conveniência para definirem suas escolhas.

Neste sentido, os resultados do presente estudo podem auxiliar a definição de estratégias a serem assumidas nas IES em termos de marketing educacional e política concorrencial, Uma vez que, através da análise dos atributos mais relevantes para escolha por cursos de pós-graduação lato sensu, os gestores podem direcionar sua atuação no mercado.

Também deve-se considerar que embora existam outros estudos buscando relacionar e mensurar os diferentes atributos que afetam as escolhas dos alunos o presente trabalho avança em termos de adicionar fatores de comunicação como motivador e relacionar todos os atributos com a concorrência com diferentes instituições.

Em termos de limitações do trabalho, ressalta-se que a pesquisa foi realizada em uma IES do interior do estado de São Paulo, não podem ser feitas generalizações a respeito dos atributos de escolha por cursos de pós-graduação lato sensu para todas as IES, mesmo que dando boas indicações para novos estudos.

Para próximos estudos sugere-se buscar compreender como se dá o processo de tomada de decisão dos alunos considerando os atributos apresentados, bem como pode-se buscar formas de avaliar a efetividade e eficiência das estratégias de marketing realizadas pelas instituições de ensino na captação de novos alunos.

\section{REFERÊNCIAS}

ALFINITO, Solange; GRANEMANN, Sérgio R. Escolha de uma IES em função da utilidade do usuário potencial: o estudante. In: ROCHA, Carlos H.; GRANEMANN, Sérgio R. (Org.). Gestão de instituições privadas de ensino superior. São Paulo: Atlas, 2003.

ALVES, Helena M. B. O marketing das instituições de ensino superior: o caso da Universidade da Beira Interior. Dissertação (Mestrado em Gestão) - Departamento de Gestão e Economia, Universidade da Beira Interior, Covilhã, Portugal, 1999 
BANDEIRA, Mariana L.; GONÇALVES, Carlos A. G.; VEIGA, Ricardo T.; HUERTAS, Melby K. Z. Avaliação da qualidade do ensino de pós-graduação: elementos para a construção e validação de um instrumento de pesquisa. Foz do Iguaçú, XXII Encontro Anual da Associação Nacional de Pós-Graduação em Administração (ENANPAD), 1998.

BERGAMO, Fabio V.; PONCHIO, Mateus C.; ZAMBALDI, Felipe; GIULIANI, Antonio C.; SPERS, Eduardo E. De prospect a aluno: fatores influenciadores da escolha de uma instituição de ensino superior. BASE - Revista de Administração e Contabilidade da Unisinos, Porto Alegre, v. 7, n. 3, set. 2010.

BRAVIN, Flavia H. D. A.; IKEDA Ana A. Uma discussão sobre o composto de marketing no contexto educacional. Pensamento \& Realidade, São Paulo, v. 25, n. 1, 2010.

BRONEMANN, Márcia R.; SILVEIRA, Amélia. Marketing em instituições de ensino superior: a promoção do processo seletivo. In: MELO, Pedro A.; COLOSSI, Nelson (Org.). Cenários da gestão universitária na contemporaneidade. Florianópolis: Insular, v. 1, 2004.

CAETANO, Jean G.; OLIVEIRA E SILVA, Roberta D. A publicidade nas instituições de ensino superior do alto e médio vale do Itajaí. Porto Alegre, XXVII Congresso Brasileiro de Ciências da Comunicação, 2004.

CARVALHO, Baiard G.; BERBEL, Mauricio C. Marketing Educacional: como manter e conquistar mais alunos. 2 ed. São Paulo: Alabama, 2001.

CIURANA, Anna M. G.; LEAL FILHO, Walter. Education for sustainability in university studies: experiences from a project involving european and latin american universities. International Journal of Sustainability in Higher Education. Bingley (Reino Unido), v. 7, n.1, 2006.

COBRA, Marcos; BRAGA, Ryon. Marketing educacional. 2. ed. São Paulo: Cobra Editora e Hopper Editora, 2004.

COSTA, Francisco José. A influência do valor percebido pelo cliente sobre os comportamentos de reclamação e boca a boca: Uma investigação em cursos de pósgraduação lato sensu. Tese (Doutorado em Administração) - Escola de Administração de Empresas de São Paulo, Fundação Getúlio Vargas, São Paulo, 2007.

COUTINHO, Fernando C. C. Avaliação da qualidade dos serviços de uma instituição de ensino superior. Dissertação (Mestrado em Administração) - Escola de Administração, Universidade Federal da Bahia, Salvador, 2007.

DESSOTTI, Leandro; PAVAN, André A.; CUNHA, Hercules F. O marketing educacional aplicado nas instituições de ensino superior como ferramenta de competitividade. Conexão Eletrônica, Três Lagoas, v.10, n.1, 2013.

FRANCO, Edson. Marketing educacional. In: Seminário Gestão de IES: da teoria à prática. Fundação Nacional de Desenvolvimento do Ensino Superior Particular. Brasília: Funadesp, 2000. 
GOMES, Giancarlo; GIOTTO, Olivo T.; DOMINGUES, Maria J. Educação continuada em administração: uma visão dos alunos concluintes em duas IES do sul do Brasil. VII Congresso Virtual Brasileiro de Administração (CONVIBRA), 2010.

INEP - INSTITUTO NACIONAL DE ESTUDOS E PESQUISAS EDUCACIONAIS ANÍSIO TEIXEIRA. Censo da educação superior 2014: Notas estatísticas. Distrito Federal, 2015.

KIMURA, Herbert; BASSO, Leonardo F. C.; MARTIN, Diógenes M. L. Redes Sociais e o Marketing de Inovações. RAM Revista De Administração Mackenzie. v. 9, n. 1, 2008.

KOTLER, Philip; ARMSTRONG, Gary. Princípios de Marketing. 12.ed. Rio de Janeiro: Prentice Hall, 2007.

KOTLER, Philip; FOX, Karen F. A. Marketing estratégico para instituições educacionais. São Paulo: Atlas, 1994.

KOTLER, Philip; LEVY, Sidney J. Broadening the Concept of Marketing. The Journal of Marketing. American Marketing Association, vol. 33, n. 1, jan, 1969.

LIMA, Manolita C. Globalização ou internacionalização do ensino superior? Revista da ESPM, São Paulo, v. 13, n. 4, jul/ago, 2006.

MAINARDES, Emerson W.; DESCHAMPS, Marcelo; DOMINGUES, Maria J. C. S. Estratégias de captação de alunos para cursos de graduação em administração: um estudo sobre fatores de atratividade de estudantes. Rio de Janeiro, X Simpósio de Administração da Produção, Logística e Operações Internacionais (SIMPOI), 2007.

MALHOTRA, Naresh K. Pesquisa de marketing: uma orientação aplicada. 3. ed. Porto Alegre: Bookman, 2001.

MAVONDO, Felix T.; CHIMHANZI, Jacqueline; STEWART, Jillian. Learning orientation and market orientation: relationship with innovation, human resource practices and performance. European Journal of Marketing, v. 39, n. 11/12, 2005.

MENEGHELLI, Priscila. J. M. Atributos de atração para cursos superiores: um estudo com alunos ingressantes. Dissertação (Mestrado) - Programa de Pós-Graduação do Centro de Ciências Sociais Aplicadas da Universidade Regional de Blumenau, Blumenau (SC), 2011.

MICHAEL, Steve O. American higher education system: consumerism versus professorialism. International Journal of Education Management. v. 11, n. 3, 1997.

MIRANDA, Cristina M. S.; DOMINGUES, Maria J. C. S. Razões para escolha de uma IES: uma abordagem sobre o perfil sócio-econômico de alunos interessados em cursar administração. São Luís, XVII Encontro Nacional de Cursos de Graduação em Administração (ENANGRAD), 2006. 
MONTEIRO, Luiz A. S. A pós-graduação lato sensu em administração no Brasil: um estudo de caso. Assunção, VIIII Colóquio Internacional sobre Gestão Universitária nas América do Sul, 2008.

MUND, Aniceto L.; DURIEUX, Fabrícia; TONTINI, Gérson. A influência do marketing na opção do aluno pela Universidade Regional de Blumenau. Campo Grande, XXIV Congresso Brasileiro de Ciências da Computação, 2001.

MURIEL, Wille; GIROLETTI, Domingos. Captação e retenção de alunos no ensino superior. Cultura e Fé, Porto Alegre, v. 33, n. 128, jan./mar. 2010.

NUNES, Getulio T.; LANZER, Edgar A.; SERRA, Fernando R.; FERREIRA, Manuel P. Emergência do marketing nas instituições de ensino superior: um estudo exploratório. Análise, Porto Alegre, v. 19, n. 1, jan/jun, 2008.

PALACIO, Asunción B.; MENESES, Gonzalo D.; PÉREZ, Pedro J. P. The configuration of the university image and its relationship with the satisfaction of students. Journal of Educational Administration, v. 40, n. 5, 2002.

PEREIRA, Maíse S.; FORTE, Sérgio H. A. C. Visão baseada em recursos nas instituições de ensino superior de Fortaleza: uma análise ex-ante e ex-post à LBD/96. Revista ANGRAD, Rio de Janeiro, v. 7, n. 3, jul/ago/set, 2006.

PIÑOL, S. T. Janela do cliente-aluno nos cursos de pós-graduação. Florianópolis, IV Colóquio Internacional sobre Gestão Universitária na América Do Sul, 2004.

SCAGLIONE, Vera L. T.; PIZA, Vera T. Estratégais de marketing aplicadas a instituições de educação superior privadas. Gestão Universitária na América Latina (G.U.A.L), Florianópolis, v. 4, n. 2, mai/ago, 2011.

SCARPIN, Marcia R. S.; DOMINGUES, Maria J. C. S.; SCARPIN, J. E.. Fatores de atração como diferencial competitivo nos cursos de pós-graduação lato sensu. São Paulo, XIII SEMEAD - Seminários em Administração, 2010.

SCARPIN, Márcia R. S.; SCHARF, Edson R.; FERNANDES, Josiane. O valor da marca na escolha do curso de pós-graduação lato sensu de uma IES do Vale do Itajaí - SC. São Paulo, XIV SEMEAD - Seminários em Administração, 2011.

SEEMAN, Elaine D.; O'HARA, Margaret. Customer relationship management in higher education: Using information systems to improve the student-school relationship. Bingley (Reino Unido), Campus-Wide Information Systems, v. 23, n. 1, 2006.

TAUIL, Amire; MAINARDES, Emerson W. Fatores determinantes na escolha de cursos de pós-graduação lato sensu. Buenos Aires, XIII Colóquio Internacional sobre Gestão Universitária nas Américas, 2013.

TELLES, Renato. A efetividade da "matriz de amarração" de Mazzon nas pesquisas em Administração. Revista de Administração, São Paulo v.36, n.4, outubro/dezembro 2001. 
THIES, Rosemar B.; BIANCHI, Renata C. A visão dos formandos em administração e dos empresários com relação ao mercado de trabalho. II Congresso Virtual Brasileiro de Administração (CONVIBRA), 2005.

TREVISAN, Rosi M.. Marketing em instituições educacionais. Revista PEC, Curitiba, v.2, n.1, jul, 2001.

VIEIRA, Valter A. As tipologias, variações e características da pesquisa de marketing. Revista FAE, Curitiba, v.5, n.1, jan/abr, 2002.

WALTER, Silvana A.; TONTINI, Gerson; DOMINGUES, Maria J. C. S. Identificando oportunidades de melhoria em um curso superior através da análise da satisfação dos alunos. Brasília, XXIX Encontro Anual da Associação Nacional de Pós-Graduação em Administração (ENANPAD), 2005. 